\title{
How Many Meals Should I Eat Each Day? ${ }^{1}$
}

\author{
Wendy J. Dahl and Zainab Alyousif ${ }^{2}$
}

For older adults who want to stay healthy, it's a common question: should I eat three meals a day, or is two meals adequate? Also, should I eat snacks between my meals?

Before you decide how many meals you should eat, let's define the terms "meal" and "snack."

A meal is an eating occasion such as breakfast, lunch, or dinner. Eating a meal can occur anywhere, at home or away. A meal is considered larger than a snack.

A snack is a food or beverage that is eaten between meals and is usually smaller than a meal. Often snacks require little or no preparation, such a piece of fruit, bowl of cereal, or cheese and crackers.

For healthy older adults, the number of meals may not matter as much as the total food eaten in a day. It is the nutritional quality of your meals and snacks and the total calories consumed that are most important. Snacking is fine as long as healthy choices are made. However, people with health conditions such as diabetes may need to follow a meal or snack pattern prescribed to them by a dietitian or doctor.

The United States Department of Agriculture's MyPlate is a simple meal planning guide to help you plan healthful meals using foods from the five food groups: fruits, vegetables, protein, grains, and dairy. Currently, the American diet is low in fruits, vegetables, and dairy products and high in calories, added sugars, saturated fat, and sodium.

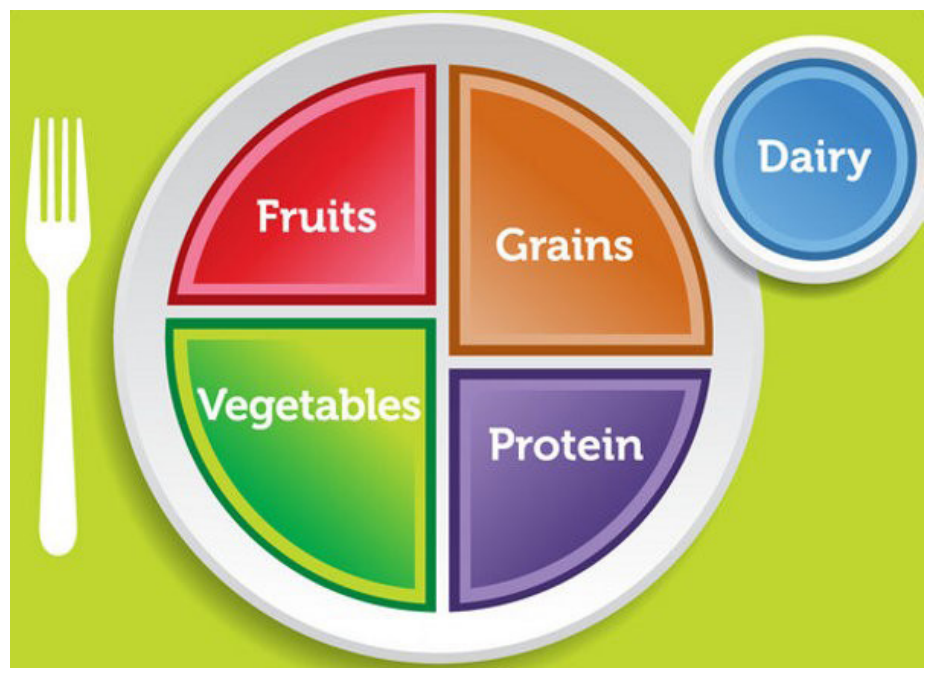

Figure 1. MyPlate (https://www.choosemyplate.gov/)

Most Americans meet or exceed their recommended intake for total grains but fall short for whole grains. It is recommended that a meal should include at least three of the five food groups (see Figure 1). A snack should include foods from one or more of the recommended food groups.

Eating well and making healthy choices are important no matter what your age may be. However, as you age, your body changes and eating a variety of foods becomes even more important. Choosing foods from all food groups will help you get the nutrients you need to promote good health and prevent illness.

The Dietary Guidelines for Americans suggests that people 50 years of age and older choose the following foods and

1. This document is FSHN18-10, one of a series of the Food Science and Human Nutrition Department, UF/IFAS Extension. Original publication date August 2018. Visit the EDIS website at http://edis.ifas.ufl.edu.

2. Wendy J. Dahl, associate professor; and Zainab Alyousif, student; UF/IFAS Extension, Department of Food Science and Human Nutrition, Gainesville, FL 32611. 
amounts every day (USDHHS and USDA 2015). Individual daily requirements will vary with age, activity, and body size. Also, men usually need more calories, and thus more food, than women. Recommended energy intakes range from about 1,600 calories per day for a sedentary older woman to 2,600 calories for an active older man. Below are some general guidelines for food group intakes.

- Fruits: $1 \frac{1 / 2}{2}$ to $2^{1 / 2}$ cups

- Vegetables: 2 to $3 \frac{1}{2}$ cups

- Grains: 5 to 10 ounces

- Protein: 5 to 7 ounces

- Dairy: 3 cups of fat-free or low-fat milk

- Oils: 5 to 8 teaspoons

- Limit solid fats, added sugars, and sodium (salt)

Fruits and vegetables are important for the older adult, as they provide vitamins, minerals, fiber, and energy. Grains, particularly whole grains, provide vitamins, minerals, and fiber, as well as carbohydrates for energy and some protein. Protein-rich foods, such as meat, poultry, fish, and legumes, are especially critical to maintain muscle and strength as we age. Dairy products, such as cow's milk, provide protein as well as vitamin $\mathrm{D}$ and calcium, nutrients that may be low in the diets of older adults.

\section{Summary}

Healthful eating is not so much about the number of meals and snacks one consumes, but the types and amounts of foods eaten. Aiming to meet the recommended servings of food groups, i.e., fruits, vegetables, grains, protein, and dairy will help promote good health and prevent illness.

\section{Reference}

USDHHS and USDA. 2015. "2015-2020 Dietary

Guidelines for Americans. 8th Edition." http://health.gov/

dietaryguidelines/2015/guidelines/ 